Mayo Clinic, Rochester, Minn. ; to Dr. Karl Miescher of Ciba, Basle; to Dr. E. Oppenheimer of Ciba Pharmaceutical Products, Summit, N.J.; to Dr. A. S: Cook of Ayerst; McKenna and Harrison, Montreal ; to Dr. E. Schwenk of Schering Corporation, Bloomfield, N.J. ; to Dr. M. Tausk of Organon, Holland ; to Dr. O. Kamm of Parke, Davis and Co., Detroit; to Dr. F. Giral of Laboratorios Hormona and Instituto Politécnico, Mexico.

${ }^{1}$ Lipschütz, A., and Iglesias, R., C. R. Soc. Biol. (Paris), 129, 519 (1938).

"Lipschütz, A., Iglesias, R., and Vargas, L., Proc. Soc. Exp. Biol. Med., 45, $788(1940)$.

' Lipschütz, A., Cold Spring Harbor Sympos., 10 (1942).

' Lipechütz, A., Vargas, $1 .$, and Nuñez, C., Proc. Soc. Exp. Biol. Med. 48, 271 (1941).

- Lipschütz, A., and Zañartu, J., Endocrin., 81, 192 (1942).

- Lipschütz, A., and Maass, M., Cancer Res. (in the press).

'Lipschütz., A., and Schwarz, J., Cancer Res. (in the press).

- Lipschütz, A., Rev. Med. y Alim. (Chile), 5, 73 (1941).

- Lipschütz, A., Vera, O., and González, S., Cancer Res., 2, 204 (1942).

${ }^{10}$ Lipschütz, A., Rev. Canad. de Biol., 2, 92 (1943).

"Unpublished work in 'collaboration with Drs. S. Bruzzone, F. Fuenzalida, $\mathrm{R}$. Iglesias and others.

\section{THE PULSATION THEORY OF CEPHEID VARIABLES}

$\mathrm{P}$ ROF. SVEIN ROSSELAND delivered the George Darwin Lecture of the Royal Astronomical Society, on September 10, 1943, on "The Pulsation Theory of Cepheid Variables", and the address is now available (Mon. Not. Roy. Astro. Soc., 103, 5 ; 1943).

In the introduction, Prof. Rosseland refers to different types of stellar motions, the simplest type of large-scale motion being rotation round a fixed axis ; this particular problem must be considered to be still in a preliminary stage both from the theoretical and observational points of view. The expansion and contraction of a star as a whole is a second type of large-scale motion, and this can be said to be represented in the sun by the outward motion of the corona; but it is most conspicuous in Wolf-Rayet stars and novæ, where direct observation of the expansion is possible. In the case of Cepheids and other periodic variable stars, it is believed that a periodic type of expansion and contraction is at the root of the phenomena.

The problem of interpreting the behaviour of Cepheid variables was responsible for the idea that stars may perform spherical pulsations, and it is interesting to notice that Coodricke, who announced the variability of $\delta$ Cephei in 1783, was cautious enough not to attribute its variability to eclipses in a binary system, like $\beta$ Persei. It was not until 1879 that August Ritter developed a rudimentary theory of the pulsation $r y p o t h e s i s$ and suggested that Cepheids might owe their light-variation to pulsation. He made the important discovery that the slowest mode of pulsation of a homogeneous star has a period inversely proportional to the square root of its density, and also found that this mode of pulsation becomes unstable when the ratio of specific heats falls below 4/3-a result which holds, not only for the Cepheids, but for other gaseous stars as well. Unfortunately, Ritter's suggestion received little attention, and in 1894, when Belopolsky discovered the periodic variation in the position of the lines in the spectrum of $\delta$ Cephei, this fact was interpreted as a confirmation of the binary star theory of Cepheids.

Plummer was the first to show that the binary hypothesis was very doubtful, and in the following year, 1914, Shapley ruled out the hypothesis by an analysis of observational data, suggesting the pulsation hypothesis as an alternative. His most convincing argument was that if a companion to a Cepheid were responsible for the light-variation, the size of the orbit would be so small that the companion would necessarily move well inside its primary. Eddington took up the subject of the pulsating hypothesis in 1917-18 and raised it to the rank of a mathematical theory in which quantitative issues are involved. A few observational facts about Cepheids were definitely established by that time; thus the periods, the general form of the light-curve, the velocity-curve, and the period-luminosity relation were known. More information is now available on the correlation between the period and the mean density, enabling a preliminary check to be made on the theoretical law; and in addition, much more material can be utilized concerning the form of the light- and velocity-curves.

The problem of the pulsation theory is beset with many difficulties, and it has been found necessary to approach it in successive steps. In the first step, the theory was developed within the framework of ordinary acoustics, and in this case wave motions are linearly superposed to form compound waves, the oscillations being assumed adiabatic. Within the acoustic limit the relation

$$
P \sqrt{ } \rho=K
$$

holds, where $\boldsymbol{P}$ is the period and $p$ the mean density, $K$ being a constant for each stellar model, but differing for different models. When $\log P$ is plotted against $\log \rho$, the plot should reduce to a straight line forming an angle of $45^{\circ}$ with the axis, for stars of the same model, and stars of the short-period and Cepheid type fall very closely along a line which is parallel to this line, but well to the right of it, thus confirming theoretical expectations. The long-period stars fall widely off the line, still farther to the right. and the only group that conforms to expectations is the small group of short-period variables in Messier 3, discovered by Schwarzschild. Two possible ways of overcoming the difficulty are suggested. If it is admitted that different groups of stars have different values of the ratio of specific heats, a drop from $1 \cdot 6$ to 1.4 would suffice to bring the theoretical line into coincidence with the observed Cepheid line, but a considerably greater alteration would be necessary to bring the theoretical line into coincidence with the observed long-period line. No physical basis exists for such an assumption regarding the alteration in the specific heats ratio. Another suggestion is that the stellar model should be altered so that the central density would be 10 times instead of 54 times the mean density, but even such a drastic alteration would not explain the position of the long period variables in the diagram.

After discussing these difticulties, Prof. Rosseland deals with his own work, in which the acoustic approximation is abandoned. In the case of an ordinary pendulum, infinitely small oscillations are sinusoidal, and the period is independent of the amplitude, like small oscillations of a star. When the swings of a pendulum increase, the oscillations cease to be sinuosidal and are represented by elliptic functions, the period increasing at the same time. If a curve is plotted giving velocity against time, the change in its shape enables us to infer the length of the period, and we might expect, in a general way, that the 
same situation holds for the pulsations of a atar. As the velocity curve differs more and more from a simple sine curve, so the period may be expected to lengthen relative to the period computed from the elementary theory. Eddington dealt with the subject of an extended pulsation theory in 1918, and showed that theary predicts a faster rise of the velocity to a maximum than the subsequent drop to a minimum, and in 1937 Miss Kluyver extended the investigation to include a dependence of period on amplitude. Prof. Rosseland develops his theory of 'anharmonic pulsations" in an appendix, and finds that the semiamplitude of oscillation would have to be a quarter of the radius of the star-a value $4-5$ times too great for most of the Cepheids. He admits that there is a considerable discrepancy to bridge, and it does not appear that this can be done by varying the model. It can probably be done if the calculations are extended to include more coupling terms in the equations.

In conclusion, Prof. Rosseland points out the incompleteness of the pulsation theory in its present stage, and even the 'anharmonic thoory' must still be considered to be in its infancy. As already pointed out earlier in this summary, there is a problem connected with the separation of the Cepheids, longperiod variables and the $M 3$ group, and no solution has yet been attained. It is suggested that inherent physical differences between the stars of these three groups exist. Regarding the phase retardation of luminosity, the pulsation theory has little to say, though it is admitted that Eddington's suggestion about the hydrogen convection zone may finally lead to a solution of this problem. In this connexion further work on the anharmonic pulsations may be important, and the same applies to the period-luminosity law, an interpretation of which has not yet been afforded. The fact that the pulsation theory has survived for nearly thirty years against hard tests is an indication of the soundness of its basic assumptions, and it will remain a fruitful field of work in the future development of astrophysies.

\section{NATIONAL RESEARCH COUNCIL OF CANADA}

THE annual report of the National Research Coumcil of Canada*, 1941-42, includes the report of the president, the finaneial statement for the fiscal year 1941-42, as well as the reports of the directors of the various divisions, the Gauge Measurement Laboratory, the Radio Board, the Section on Codes and Specifications and the Research Plans and Publications Section. Practically all the activities of the National Research Council in 1941 were directed to the study and solution of problems immediately connected with Canadi's growing war effort, and the Council has been officially designated as the Research Station of the Royal Camadian Navy, the Army and the Air Force, and is shown as a civil establishment in the records of the Department of National Defence.

The Divisions of Chemistry and of Applied Biology have been engaged largely in selecting and testing suitable materials for the use of the armed forces and in the Physics, Electrical and Meohanical Enginearing Depertments, the design and development of new detecting deviees to locate aircraft, submarines, mines,

* Twenty-fifth Annual Report of the National Research Council of Canada, 1941-42. (N.R.C. No. 1089.) Pp. 33. (Ottawa.) and other enemy equipment have been carried forward with much success. Engines, airaraft and other items of equipment used in mechanized warfare have been tested on a large scale, and additional staff and facilities have been provided to meet the new require. ments, the staff of the Council working in the Ottawa area numbering 803 on March 31, 1942, as against 308 in July 1939, the greatest increase in numbers being in the Division of Physics and Electrical Engineering. New buildings have been constructed to house the aeronautical and hydraulic laboratories and the work of some of the other divisions. A radio field station has been established near Ottawa, and owing to the large increase in the staff of the radio section, a Radio Board has been established for the general direction of all radio research and development work in connexion with the Council's war activities. An important war service has been rendered by promoting the development in Canada of optical glass manufacture for precise optical parts of military equipment.

The Division of Biology and Agriculture, which has been renamed the Division of Applied Biology, has devised methods for converting large insulated cargo holds into refrigerating space without delaying the vessel to provide an immediate solution for the acute bacon transport problem, and a standard curing practice has been developed in Canadian package plants which yields a more stable product. Other work in progress in this Division relates to the treatment of shell eggs to prevent deterioration during shipment at ordinary temperatures, tests on the quality of dried eggs and the preparation of specifications for shipping, investigations on drying pork, canning poultry, vitamin content of flour and the development of rapid growing, easily propagated forest trees; vegetative propagation has reached the stage when cuttings of Norway spruce, white spruce and white pine can be successfully rooted on a practical scale.

In the Division of Chemistry, the Plastics Laboratory of the Colloidal Section, which was being equipped at the outbreak of war, has carried ont a survey and experimental work on the ase of laminated wood in aircraft construction in co-operation with the Division of Mechanical Engineering. In the physical chemistry section investigations on the development of de-ieing fluids, prevention of frost deposition on aireraft, resolution of aerial photographs, etc., have continued, while the organic chemistry section has continued its general programme of researeh on alkaloids and has synthesized indicators for war gases and chemicals for other war purposes; in the preparation of some special organic chemicals, produetion has been advanced to semi-pilot plant scale. In addition to investigating produets used by almost every branch of the armed forces, including surgeons' gloves, ground sheets, gas-mask components, etc., the rubber laboratary has given much attention to rubber conservation problems and to the study of processes for synthetic rubbers. The refraetories laboratory continued its investigations of high-temperature furnace linings. Experiments on the production of metallic magnesium have been pushed forward until a process worked out in the laboratory has been sponsored in a more detailed study embodying pilat-plant operation by a group of industrialista.

Activities in the textile laboratory were largely devoted vo acceptance test work and specifications. An explosives laboratory was established late in 1941 to carry out testing under the Explosives Act and conduct researeh on explosives and related compounds. 